\title{
SERIA A GEOGRAFIA MAIS URBANA DO QUE SE CALCULA?
}

\author{
Arilson Favareto*
}

Que a definição de objetos científicos sempre foi e continuará sendo motivo de polêmicas entre diferentes tradições teóricas ou disciplinares não resta a menor dúvida. Que por trás destes embates está em jogo uma disputa que envolve a hierarquia dos objetos e a legitimidade de quem está autorizado a falar sobre aquela instância do mundo, também isto é algo que está na base de toda a tradição da sociologia da ciência, desde Merton até Bruno Latour. O que não é tão comum, no entanto, é ver demonstrações de como a crença na hierarquia de objetos, a um só tempo pertencentes ao mundo social e ao mundo intelectual, se transforma em disposições capazes de turvar por completo até mesmo o olhar de pesquisadores experimentados. Um bom exemplo disso é a resenha elaborada por uma geógrafa da Universidade de São Paulo para a Revista Geousp (número 13), em 2003, sobre o livro de José Eli da Veiga, Cidades imaginárias: o Brasil é menos urbano do que se calcula, publicado pela Editores Associados no ano anterior.

No texto, Ana Fani Alessandri Carlos, conta ter sido atraída pelo subtítulo da obra de Veiga. Mas o interesse inicial, despertado pelo teor da hipótese anunciada, acabou por dar lugar à completa desilusão com os argumentos utilizados para sustentá-la. A decepção da autora é creditada tanto ao caráter do livro uma coletânea de artigos quinzenais publicados na coluna que o economista mantinha, à época, no jornal O Estado de São Paulo-, como à própria natureza de suas teses.

Até aí, nada demais. O problema começa justamente quando a resenhista passa a expor suas críticas ao livro. O que vem a partir de então é, lembrando Thompson, um verdadeiro planetário de erros. As próximas linhas têm por objetivo corrigir as principais distorções apresentadas pela autora e destacar as verdadeiras contribuições, insuficiências e questões deixadas em aberto pelo livro de Veiga.

\section{O que o livro é e os riscos da leitura frugal}

Em pouco mais de trezentas páginas o livro traz uma coletânea de artigos organizados em quatro partes: Cidades imaginárias, dedicada ao tema do desenvolvimento rural; Choque de mentalidades na agropecuária, devotada à análise de aspectos relativos às diferentes formas sociais de produção existentes no meio rural brasileiro; Licença para poluir, que trata da relação entre economia e meio ambiente; Desenvolvimento e empregos, onde a preocupação alcança temas como o trabalho, a coesão social e seu papel nos destinos de países e regiões; e, por fim, Futuro da economia global, que como o próprio título anuncia, aborda processos sociais e econômicos relativos àquilo que se convencionou chamar por globalização.

Esta organização do livro reflete, na verdade, alguns dos campos de preocupação cobertos pelo programa de pesquisas conduzido pelo autor na Faculdade de Economia e no Programa de Pós-Graduação em Ciência Ambiental da USP. O fato de tratar-se de textos curtos, contudo, não deve ser tomado como sintoma de superficialidade. Os artigos reúnem, 
em geral, um bom equilíbrio entre um conhecimento empírico sólido sobre os problemas abordados, a citação e constante referência a estudos e pesquisas brasileiras e internacionais de ponta, e - traço marcante um questionamento ao viés urbano e economicista de abordagem destes mesmos temas.

Por tudo isso não é recomendável, como faz a resenhista, uma leitura frugal, "no café da manhã". Ao contrário, o principal mérito de Cidades imaginárias é introduzir, em linguagem acessível mas não ingênua ou inconsistente, problemas de ordem política e científica há tempos naturalizados por pessoas e instituições. Entre eles, o problema da definição do que é urbano e do que é rural, um dos pontos fortes da obra e alvo dos principais questionamentos da resenhista.

Mas antes de passar às críticas é importante restabelecer algumas das principais teses do autor. Se fosse possível resumir a três afirmações as principais mensagens contidas no livro de José Eli da Veiga, elas talvez pudessem ser sintetizadas como segue.

Primeira idéia-força: O rural continua a ser uma categoria pertinente de classificação. Isto se justifica tanto pela permanência da ruralidade como característica marcante de boa parte dos espaços nos países da periferia do capitalismo, mas também no chamado núcleo central da economia mundial, como pela possibilidade de se definir teoricamente o que é o rural, distinguindo-o do urbano. Ao operar esta distinção, não se deve porém dicotomizar os dois pólos, pensando-os como opostos que são um a negação do outro. Em vez disso, a afirmação da diferença entre ambos deve servir para realçar o que lhes é específico e, ao mesmo tempo, para identificar as instâncias empíricas através das quais se possa vislumbrar o conteúdo relacional dos dois domínios. Esta tese contrasta com aqueles que vêem o rural como mero resíduo do urbano, ou com aqueles que o tomam como sinônimo da agricultura. Veiga discute as classificações (estatísticas mas também políticas e teóricas) utilizadas no Brasil e em outras partes do mundo para mostrar como é pura ficção qualquer afirmação que aponte para um "fim do rural", daí o título do livro.

Segunda idéia-força: As características do tecido social e econômico de um território importam na configuração do campo de possibilidades em que se inscreve seu futuro. As regiões que têm em sua base estruturas sociais mais diversificadas e desconcentradas, como é o caso de vários espaços de predomínio da agricultura familiar ou de pequenas e médias empresas, apresentam melhores possibilidades de criar instituições e articulações capazes de trazer a dinamização econômica acompanhada da melhoria das condições de vida da maior parte da população, em vez de um crescimento concentrado nas mãos de poucos, como é característico nos territórios baseados em grandes e especializadas empresas. Mais uma tese que contraria tanto o senso comum, maravilhado com os êxitos recentes da exportação brasileira de grãos, como muitas vertentes explicativas da ciência econômica, para quem economias de escala são muitas vezes o único critério de eficiência.

Terceira idéia-força: Os termos em que se dará a construção de um novo padrão de relação entre sociedade e meio-ambiente, onde as formas de uso social da natureza não sejam marcadas pela degradação, ainda não é algo claramente inscrito nos quadros teóricos e programáticos das sociedades contemporâneas. Mas este tipo de preocupação já é forte o suficiente para dar origem a esforços de internalizar a dimensão ambiental em aparatos legais, no caso do Estado, e científicos, no caso do campo intelectual. É nesse sentido que a expressão desenvolvimento sustentável deve ser entendida não como conceito, muito menos como teoria, mas sim como um desafio para o novo século. Não uma utopia vazia, como algo que não tem lugar (u-topos), mas como uma idéia-força capaz de mobilizar esforços e tentativas de materializá-la. Isto não passa pela mercantilização da natureza, como defende uma 
importante corrente da economia, mas sim pela criação de instituições capazes de moldar a ação humana numa direção mais conciliadora com a necessidade de preservar os recursos naturais. E a criação de instituições é, em geral, um processo longo onde interesses específicos se chocam e se compõem de diferentes maneiras.

\section{Erros de interpretação e a verdadeira polê- mica em questão}

Quando se vê a magnitude destas teses, entende-se porque a leitura frugal do livro pode levar a graves incompreensões e equívocos. É o que ocorre com a resenha citada. São duas as críticas teóricas relevantes emitidas pela resenhista. A primeira sugere que "os argumentos desenvolvidos nos artigos do livro caminham na direção oposta ao que o autor quer provar. (...) ao mesmo tempo em que assinala o fato de que o Brasil é menos urbano do que se calcula, reconhece que há, hoje, uma profunda transformação nas relações cidade/campo, mas não enfrenta a necessidade de desvendamento do conteúdo e sentido destas transformações". A segunda crítica, por sua vez, diz respeito ao uso de categorias e idéias como ecossistema e desenvolvimento sustentável, consideradas "banalizadoras", "pura ideologia". Vejamos os argumentos.

Boa parte dos comentários da resenhista são direcionados à tipologia dos espaços urbanos e rurais elaboradas pelo autor do livro. Nela são utilizados três critérios. O primeiro deles é a densidade demográfica: ela é utilizada como proxy do grau de artificialização de um espaço. Como nos espaços rurais o peso da natureza é maior, considera-se que nas áreas de baixa densidade há uma menor pressão pela alteração do meio-ambiente. Esta é uma maneira de trazer a variável ambiental para dentro do modelo explicativo. Afinal, é inegável que o esgotamento de recursos naturais esteve na base do declínio de grandes civilizações ao longo da história, com bem o demonstram trabalhos consagrados como os de Michel Mazoyer ou de Jared Diamond. Mas este não é o único critério utilizado por Veiga, a ele se somam outros dois: o tamanho da população e a localização. Isto porque se considera que mesmo áreas que poderiam ser consideradas rurais pelo critério estrito da densidade estão expostas à atratividade de centros urbanos e aglomerações metropolitanas. Com isso, são ali considerados rurais os municípios com densidade inferior a 80 habitantes $/ \mathrm{km} 2$, com população inferior a 100 mil habitantes, e que não pertençam a aglomerações urbanas nãometropolitanas ou regiões metropolitanas. Aqueles municípios pequenos (menos de cinqüenta mil habitantes) mas densos demograficamente (mais de 80 hab./km2) são considerados ambivalentes, por estarem na fronteira entre o anel rural e os três anéis urbanos. O primeiro anel urbano é formado por centros isolados: grandes cidades com mais de cem mil habitantes. O segundo pelas aglomerações urbanas que mesmo apresentando funcionalidades integradas e muitas vezes conurbação, não chegam a ser regiões metropolitanas. Estas últimas, as regiões metropolitanas, conformam finalmente o terceiro e último anel urbano.

Este critério de classificação se apóia, de um lado, em criteriosa pesquisa realizada pelo IBGE/IPEA/Nesur-Unicamp. E de outro, em pesquisas sobre critérios utilizados internacionalmente e sobre tendências recentes do desenvolvimento rural, sempre citados nos artigos que compõem sobretudo a primeira e a segunda partes do livro. Uma conseqüência importante do exercício empreendido por Veiga é a demonstração de que a simples mudança, nesse caso aperfeiçoamento, de critério leva a uma brutal diferença nos resultados aquilatados. No caso da aplicação da tipologia ao Brasil, a população que poderia ser considerada rural salta de $18 \%$ nas estatísticas oficiais para perto de $35 \%^{1}$.

O argumento do autor não é que a tipologia dos cinco anéis é a definição cabal do que é urbano e do que é rural, como criticado pela resenhista. O que ele mostra é justamente que a definição administrativa é insuficiente. 
Portanto, obviamente não cabe a crítica de que o autor se atém a este limite, o administrativo. Ao refazer a trajetória da classificação utilizada no Brasil, contrastando-a com a experiência internacional, Veiga contribui para desfazer aquilo que o sociólogo francês Pierre Bourdieu chamava de amnésie de la genèse, uma espécie de apagamento do contexto de origem de uma idéia ou realidade social e a evolução que ela experimenta posteriormente, até naturalizar-se como categoria inquestionável de apreensão do mundo. E é evidente, mais uma vez em oposição ao que aponta a resenhista, que as formas de classificação do mundo têm sim um razoável poder no ordenamento do real. Fazer parte de regiões metropolitanas não é critério para que determinados municípios possam ser beneficiados por certas regras e investimentos ? O sentimento, mesmo equivocado, de que a tendência dos espaços rurais é diminuir gradativamente até serem completamente engolfados pela dinâmica urbana não serve muitas vezes de justificativa para esvaziar políticas específicas destinadas aquele universo ? Ingenuidade seria imaginar que as estatísticas são apenas números, e que não há usos políticos e científicos, tanto para justificar sua montagem como na sua utilização posterior.

Em vários dos artigos que compõem o livro Veiga relata achados de suas pesquisas que corroboram a idéia de que há uma crescente interdependência entre os espaços urbanos e rurais: na forma da pluriatividade, por exemplo, com a integração entre os mercados de trabalho relativos a estes dois domínios; ou na forma das dinâmicas demográficas, com movimentos muito mais heterogêneos do que a idéia dominante de êxodo generalizado sugere. Também não faz sentido, portanto, a crítica de que o livro ignora as transformações recentes. O que ele faz, e de maneira muito veemente, é atacar a visão que o autor denomina de "tudo é urbano", à qual a resenhista claramente se filia. O que fica claro quando ela afirma que "(...) a contradição campo-cidade se desenvolve propondo uma nova contradição: centroperiferia". Sem citar um único dado empírico, esta afirmação vem embasada em uma tautologia. A contradição teria se deslocado da maneira apontada "porque a urbanização generalizada tem como devir a sociedade urbana como horizonte". E mais adiante conclui, afirmando que "(...) este processo produz profundas mudanças, criando uma nova identidade que escapa ao local (e mesmo ao nacional), apontando para o mundial como horizonte e tendência", seja lá o que isso quer dizer.

De resto, uma leitura mais atenta poderia evitar erros, como dizer que o autor conclui que $3 \%$ da população brasileira seria rural, quando a afirmação correta é que essa cifra ficaria acima de $30 \%$. Ou quando tenta transcrever os critérios de corte utilizados pelo autor na referida tipologia, embaralhando por completo os argumentos e parâmetros.

A segunda crítica empreendida pela resenhista, como assinalado acima, diz respeito ao uso de noções e idéias como ecossistema e desenvolvimento sustentável. É bem verdade que ambas ocupam um lugar de destaque nos argumentos de Veiga, mas é errado dizer que seus argumentos são delas deduzidos. A própria tipologia dos espaços rurais e urbanos incorpora a dimensão ambiental, mas se funde a outros critérios de ordem estrutural e funcional. Da mesma forma, as três últimas partes do livro, às quais a resenhista não faz menção, trazem várias considerações de ordem geopolítica e, em muitas vezes, são até perceptíveis traços de uma certa influência marxista. Os dois autores que exercem influência marcante ao longo do conjunto de artigos que conformam o livro são Amartya Sen e Douglass North. Dizer que nestas duas vertentes temas como desigualdade e conflitos estão ausentes seria, no mínimo, desconhecer o alcance de suas teses.

Vale à pena, aliás, citar o livro mais recente de Veiga - Desenvolvimento sustentável: o desafio do século XXI (Ed. Garamond, 2005). Onde o autor diz, com todas as letras, que a expressão desenvolvimento sustentável ainda está longe de poder ser chamada de conceito 

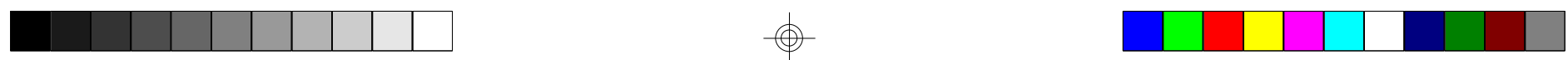

científico, embora esteja muito presente na orientação de estudos e políticas bem atuais. Ali ele diz, parafraseando Georgescu-Roegen, que no futuro a economia provavelmente será um capítulo da ecologia, e não o contrário. Ao dizê-lo, Veiga está sinalizando que a esfera da natureza não pode ser explicada com os mesmos critérios com que se analisam as trocas materiais entre os homens, e sim que esta dimensão mais estrita da economia é incrustrada e condicionada em larga medida pelo ambiente na qual elas estão inseridas, onde a natureza não é mero detalhe, principalmente quando considerada em termos de longo prazo.

Um ponto nebuloso, que no entanto não é mencionado pela resenhista, está no fato de que, se concordarmos com a idéia de que há uma interdependência entre o mundo natural e o mundo social, como fica a diferença fundamental que marca a distinção entre natureza e sociedade ? Há um primado ontológico distintivo nas relações sociais ? Se sim, como isto deve se traduzir em procedimentos epistemológicos ? É curioso que sobre isso a resenha nada diga. Assim como é curioso que a dimensão espacial dos processos sociais só seja mencionada na alusão à escala planetária dos fluxos contemporâneos... Isto justamente numa resenha elaborada por alguém da geografia, que tem por métier justamente a relação entre o homem e o espaço.

Também aqui um maior cuidado na leitura do livro poderia evitar deslizes, como dizer que, nele, "desenvolvimento vira sinônimo de crescimento", justamente quando esta é uma das teses demolidas pelo autor.

\section{Refazendo fronteiras}

O grande mérito do livro de Veiga é mexer com as fronteiras disciplinares sem precisar dizêlo explicitamente. Trata-se, pois, de uma verdadeira obra de ciência social: influências da sociologia, economia, geografia, demografia e até mesmo a ecologia estão ali presentes, dispostas de maneira muito engenhosa. Se o autor comete algum pecado, é justamente o de não respeitar divisões trazidas com a inevitável, mas ao mesmo tempo limitante, especialização disciplinar que ocorreu ao longo do último século e reatar pontes rompidas desde os clássicos. E nisso, as noções de espaço e de território quase um monopólio da geografia - Ihe são muito caras. É a partir delas que as dimensões em torno das quais se erigiriam as especializações teóricas e disciplinares são contrastadas e postas em diálogo.

Refazer fronteiras, contudo, é sempre algo que abala domínios estabelecidos, que põe em jogo os monopólios e hierarquias de objetos. Felizmente há nas ciências sociais contemporâneas outras tentativas similares que acompanham Veiga, como bem o demonstram nomes como o sociólogo italiano Arnaldo Bagnasco, o economista Ignacy Sachs, ou o geógrafo francês Bernard Kayser, para ficar apenas em alguns poucos exemplos. Estes nomes obrigam responder negativamente à pergunta que intitula esta contra-resenha: não dá para dizer que a geografia é mais urbana do que se calcula, mas que certos geógrafos (assim como parte expressiva dos economistas e sociólogos) o são, disso não resta a menor dúvida.

9 de Maio de 2005

\section{Nota}

\footnotetext{
${ }^{1}$ Nos trabalhos de Veiga esta classificação evoluiu posteriormente para a definição de regiões essencialmente rurais, relativamente urbanas, e predominantemente urbanas (Veiga, 2005).
} 


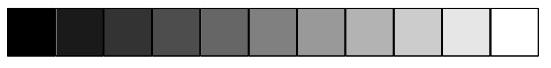

\section{Bibliografia}

CARLOS, Ana Fani Alessandri (2003). Seria o Brasil menos urbano do que se calcula?. Revista Geousp, n. 13. Consultado em www.geografia.fflch.usp.br/ publicacoes/ geousp/geousp13.
VEIGA, José Eli (2003). Cidades imaginárias: o Brasil é menos urbano do que se calcula. Campinas: Ed. Autores Associados.

VEIGA, José Eli (2005). Desenvolvimento sustentável: o desafio do século XXI. Rio de Janeiro: Ed. Garamond. 
